\title{
Educational Robotics as an Effective Use of Technology to Enhance Learning
}

\author{
https://doi.org/10.3991/ijoe.v17i06.22401
}

Yasmeen Nzam Abu Mukh ( $\bowtie)$

Al-Qasemi Academic College, Baqa Al-qarbia, Israel

yasmeena 26@hotmail.com

\begin{abstract}
Many studies provide that students who learn through participation technology, while participating in the educational process, especially in magic robot programs, make decisions in a magical way (at least this is what some students think before they know about programming and sensors) It attracts students and picks them up, and this It is the reason why they are busy with technology-enhanced learning inside warfare, with a special focus on educational robot programs [6] , and it should be noted that some research highlights that some valuable comments and ideas will not only inspire future exploration in this field, but also To reassess critical evaluation of programs that may not live up to your ideal.
\end{abstract}

Keywords - Robotics, education, pedagogy, technology, STEM

\section{Introduction}

The paper examines educational robotics (ER) as an effective use of technology to facilitate learning processes in STEM/STEAM areas and to improve and develop learners' skills, habits, competencies, performance, attitudes, and etiquette.

\section{Educational Robotics: An Overview}

Educational robots (ER) can be briefly defined as an emerging field of technologyenhanced learning (TEL) where learners are presented through a variety of activities for robotics and programming, often as part of what is called STEM education (science, technology, and engineering, Mathematics) or STEAM (Science, Technology, Engineering, Arts, and Mathematics), an educational model in which the aforementioned disciplines are taught naturally for the practice of theory ([1], [8]).

Over the past decade, the value of using robots in learning has become increasingly evident. Angnoletti et al [1] cites two main advantages: (1) "Young people learn quickly and easily if they deal with material things more than just working on formulas and abstractions, as if the youth were simply committed to computer programming"; (2) "(Making) intelligent machine work improves motivation during the learning process." [2] For its part, robots envision, within their TEL concept of 
"smart education", as one of the most effective means to make "the learning process creative and innovative, and enhanced the acquisition of existing skills and competencies" which in turn, it leads to "new solutions that enhance learning."

In general, previous academic work indicates that educational robots are effective across a wide range of educational significance. Whereas, many studies confirm the usefulness of robotic interventions in developing critical cognitive skills such as computational reasoning, which Roberts [7] identified as "the thought processes involved in formulating a problem and generating a set of solutions in a way that humans or computers can understand" [1], and in teaching basic technological competencies such as computer programming and coding. Others point to ER contributions in areas such as: learner motivation, participation and retention [3]; Inclusive education (and assistive technology) that includes dimensions such as special needs, socio-economic status, cultural diversity and gender balance, teacher education, "as a tool for promoting constructivists (Piaget) and construction (papier) and the resulting innovative teaching and learning methodologies" multidisciplinary collaborative work and creativity, And foster a wide range of skills that are seen as essential to navigating life in the 21 st century, such as teamwork, critical thinking, self-evaluation, communication and adapting to change [9]. The existence of research in these programs and the impact of their use in the educational process and the expectations of specialists at the global level in this field, make us strongly believe in the importance of this science and the urgent need to include it in the educational process, and present it to students, especially in the early stages of life.

\section{The First Program in Robotics as an Educational Model for ER Efficiency in the STEAM Fields}

By integrating it with a different scientific group, any robot enables any teacher specializing in the management and operation of this program to have the least time he may need for training and a quick and brief knowledge. Where the creative teacher gets benefit from the contents of the teacher's guide to communicate a scientific idea, theory or concept. It also helps the teacher to enrich his scientific subjects with a range of different applications, whether they are ready in the laboratory or through creative ideas that this teacher achieves. It also helps in cooperation and partnership between teachers so that more than one teacher can participate in one project, each according to his specialization and field, to conclude to produce an integrated scientific and technical robot, and this is what encourages work and cooperation between them, First is a non-profit organization, founded in 1989 in the United States of Before Segway and Dean Kamen the inventor of IBOT there are two additional programs: FIRST LEGO League (FLL), for young participants up to third grade. At the beginning of the school year, robotic teams are organized in public schools around the world to participate in these competitions.

Gelzer [5] discusses the advantages of Robot: (1) Enables children to explore different areas of learning independently. (2) The demand to build a strategy from which to start a "systems perspective"; (3) focus on teamwork; (4) the need to meet 
deadlines and develop project management skills; (5) the need for creativity in problem solving (6) focus on Project Based Learning (7) developing "soft" skills, such as standing in front of the audience, peer leadership and self-expression orally and in writing; (8) rewarding those teams that inspire others. (9) the philosophy of "professionalism" [4]. Robot science began to spread and expand and imposed itself on many industries and applications A strong incentive for the students to enter the robot world and try to introduce all new.

\section{Educational Robotics Programs as -A Critical Perspective}

One of the challenges facing researchers and in order to gain a deeper insight into educational robotics programs, program coordinators and researchers in primary school conducted and employed only the best students in their robotics teams in addition, there was no division among middle school students [2]. However, it seems that there is a persistent lack of diversity among the participants, based on gender, race, ethnicity and socio-economic background: another point that bothered the researchers was the participation, or rather the absence, of students who did not belong to the program.

These critical observations regarding the employment of a weaker social, economic and gender group affect the degree of success of the method and its implementation in a successful educational and pedagogical manner. They have shed an important light on the constraints affecting educational robotics programs around the world and illustrate the need for major improvements in movement [4].

This is a good feature, which may help a lot to attract students to class. Because global reports indicate that it will inevitably reach us, and that the robot science revolution may really start after 2015 .

This encourages students to study and benefit from it and interact more with the classroom, especially if they learn the power robot connects with many of the modern science, including: (Nanotechnology, genetics, computers, electronics, and communications), and gives the student a strong impetus for them to learn this science, as it is necessary to reach them with the concept of possessing modern skills even if you do not want specialists in them. An example of this is what happened in computer science, where it moved from the stage of specialization to the stage of generalization, where every individual in society must master certain skills in computer science because of his entry in all areas and the need of people in all disciplines, so it became necessary to possess various computer skills So that an individual can do his job better and faster and improve production, and those who do not have computer skills are described as illiterate.

Therefore, scientists expect that those who have no experience in the field of robotics will inevitably have trouble dealing with modern technologies in schools, universities, etc. during the next 15 years. 


\section{Conclusion}

This work is considered a specific type of intervention in the field of education from the innovative side. Although pedagogical intervention and improved teaching composition in this paper have already proven to be correct, the integration of robots is still not necessarily successful. It is also possible to check whether the robot effect has not really improved learning, but the games themselves. Especially in interventions involving technology innovation. That is, intervention and enrichment will not burden children.

One of the advantages of this program is the deviation from the dry and boring style of the theoretical scientific share, and thus encouraging students to learn and love science, especially since a large percentage of students do not find real pleasure in learning science and mathematics, but in terms of application and in the robot lab, the situation differs where science merges and knowledge with fun and excitement. Whereas, through the school robotics laboratory and classroom classes, the teacher can implement and implement a range of activities and events related to robotic science closely related to it. Including the implementation of robotic scientific competitions for students, such as requiring them to design a robot in the form of a car and conduct a race between groups, thus generating a strong feeling among students of the need to research and experiment and use all means, laws and theories to reach the best result. It also enables students to participate in local, Arab and international competitions throughout the year by organizing school robot clubs and implementing after-work activities.

Although the teacher may encounter some difficulties in passing this science on by students who have learning difficulties and lack the capabilities of intuition and criticism available to natural students, or even the teacher finds that there is some criticism from parents who do not have the ability to provide tools and mechanisms necessary for their children to join this science.

Despite all this, we find that there is an appetite for this science remarkably by intensifying their efforts to spread these programs through networks or through the publication of articles.

According to my opinion, working in robotics programs contributes to time management and organization, resource identification, systems analysis, project management and other skills that students need in their working life, as shown in Figure (1): 


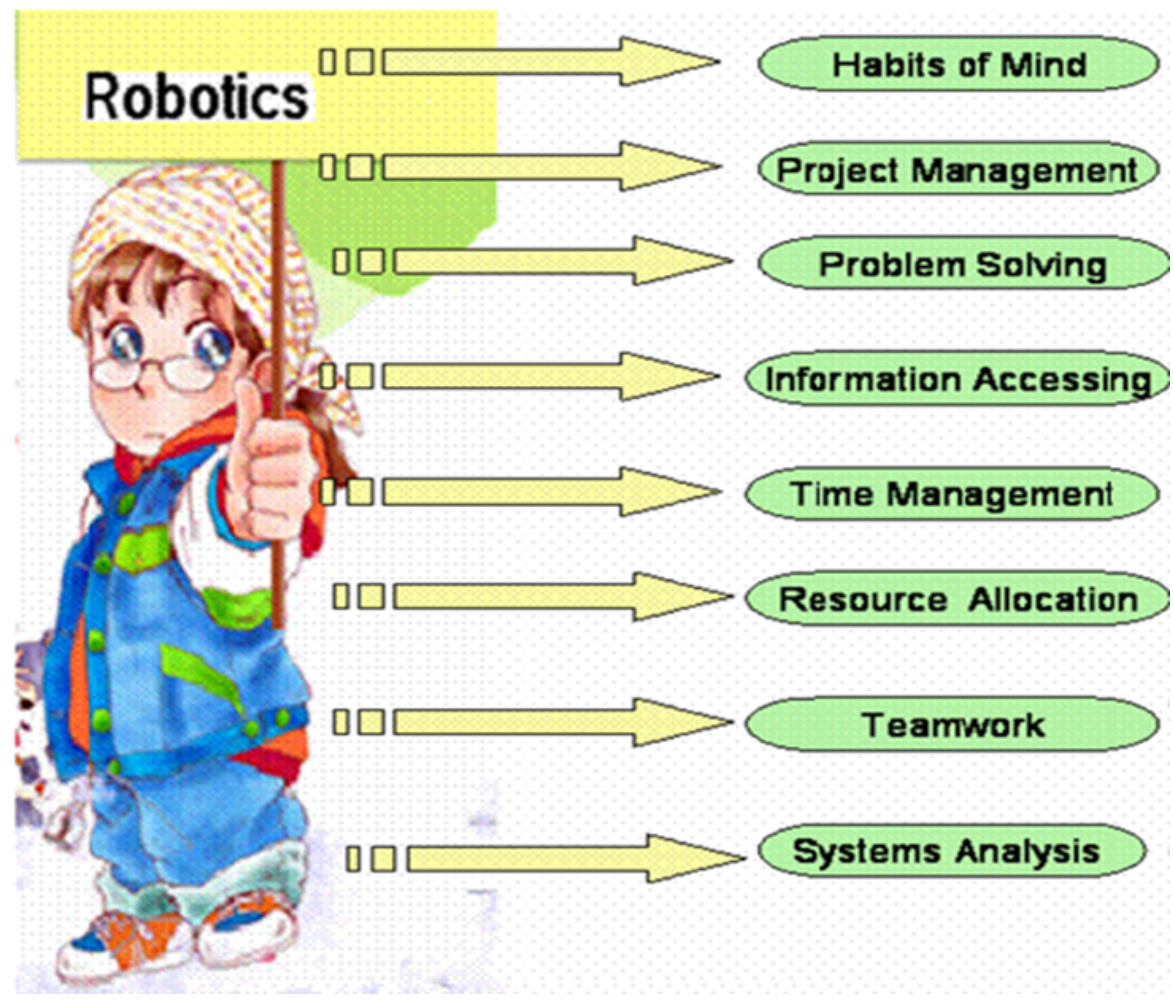

Fig. 1. The skills a student acquires using an educational robot.

\section{References}

[1] Angnoletti, M., Bianchini, D., Daniela, L., Dreimane. S., Gaudin, A., Groenwolt, P., Lourido, S., Manzani, L., Micheli, Pedemonte, G., Stein, J. \& Valli, D. (2020). Educational robotics. eMedia.

[2] Daniela, L. (2019). Smart pedagogy for technology enhanced learning. In Daniela, L. (Ed.), Didactics of smart pedagogy: Smart pedagogy for technology enhanced learning (pp. 3-22). Springer International Publishing. https://doi.org/10.1007/978-3-030-01551-0

[3] Daniela, L., \& Strods, R. (2018). Robot as agent in reducing risks of early school leaving. In L. Daniela (Ed.), Innovations, technologies and research in education (pp. 140-158). Newcastle upon Tyne: Cambridge Scholars.

[4] FIRST robotics competition. (2020). Wikipedia.

[5] Gelzer, O. (2015, 19 August). Robotics and vision: FIRST robotics programs as a tool for achieving educational objectives. Edunow.

[6] Kay, J. S. (2003) Teaching robotics from a computer science perspective. The Journal of Computing in Small Colleges, v.19 n.2, p.329-336.

[7] Roberts, R. (2019, 29 October). Robotics, computational thinking and the future of education. Medium. 
[8] Scaradozzi, D., Screpanti, L. \& Cesaretti, L. (2019). Towards a definition of educational robotics: A classification of tools, experiences and assessments. In Daniela. L. (Ed.), Smart learning with educational robotics: Using robots to scaffold learning outcomes (pp. 63-92). Springer International Publishing. Retrieved from https://www.springer.com/gp/book /9783030199128 https://doi.org/10.1007/978-3-030-19913-5 3

[9] Yanco, H.A., Kim, H.J., Martin, F. \& Silka L. (2007). Artbotics: Combining art and robotics to broaden participation in computing. Presented at the AAAI Spring Symposium: Robots and Robot Venues, Palo Alto, CA (26-28 March 2007).

\section{Author}

Yasmeen Abu Mukh, (Yasmeen) Ph.D. student at program of learning and teaching at An-Najah National University. M.A in Special Education at Tel Aviv University, Bachelor's Degree in Special Education and Arabic Language at AlQasemi Academy, Israel, Lecturer and supervisor at Al-Qasemi College in Special Education Department.

Article submitted 2021-03-03. Resubmitted 2021-04-01. Final acceptance 2021-04-02. Final version published as submitted by the authors. 